\title{
Influence of Antisense Oligonucleotides Targeting Tumor Necrosis Factor- $\alpha$ on Experimental Herpetic-Induced Chorioretinitis of Mouse Eye
}

\author{
Haifeng $\mathrm{Mei}^{\mathrm{a}}$ Yiqiao Xing ${ }^{\mathrm{a}}$ Jing Yang ${ }^{\mathrm{a}}$ Anhuai Wang ${ }^{\mathrm{a}} \mathrm{YaXu}^{\mathrm{a}}$ \\ Arnd Heiligenhaus $^{b}$ \\ a Department of Ophthalmology, Renmin Hospital of Wuhan University, Wuhan, PR China; ${ }^{\mathrm{b}}$ Department of \\ Ophthalmology at St. Franziskus Hospital, University of Duisburg-Essen, Münster, Germany
}

\section{Key Words}

Herpetic simplex virus • Antisense oligonucleotides •

Chorioretinitis

\begin{abstract}
Objective: To investigate the effect on the pathological process of topical treatment with antisense oligonucleotides (ASON) targeting tumor necrosis factor- $\alpha$ (TNF- $\alpha$ ) in experimental herpes simplex virus type-1 (HSV-1)-induced chorioretinitis of mouse eye. Methods: $50 \mathrm{BALB} / \mathrm{c}$ mice were randomly divided into two different groups (25 mice in each group). The Von Szily model was induced in mice by inoculating $1 \times 10^{5}$ plaque-forming units of HSV-1 (KOS strain) into the anterior chamber of the right eye. In one group, FITC-labeled ASON targeting TNF- $\alpha$ was injected subconjunctively into the left eye on days $-1,1$, and 4 , whereas phosphate buffer was used in the same way on the same days in another group. The clinical appearances were observed after infection each day and the eyes were examined histologically. The TNF- $\alpha$ content of retina and choroid were measured by ELISA. Results: After infection, acute inflammation appeared in the right eye of both groups. As for the non-inoculated eye, the inflammation in the ASON group was significantly decreased compared to the PBS group. The number of inflammatory cells in the ASON group was significantly lower than in the PBS group, especially in the choroid, retina and ciliary body.
\end{abstract}

The TNF- $\alpha$ content in the choroid and retina of the ASON group was diminished. Conclusion: The results suggested that TNF- $\alpha$ ASON reduced the content of TNF- $\alpha$ in mouse eyes, and this topical treatment decreased the inflammatory reaction. It may be an effective method for treating HSV-1induced chorioretinitis in the clinic.

Copyright $\odot 2009$ S. Karger AG, Basel

\section{Introduction}

\section{Acute Retinal Necrosis}

Acute retinal necrosis (ARN) syndrome is a wellknown clinical entity that was first described in 1971. It is an inflammatory disease involved in different tissues caused by several members of the herpes virus family such as herpes simplex virus-1 (HSV-1) [1, 2]. Patients always complain about red eyes, light sensitivity, eye pain and blurred vision. After examination many infiltrated inflammatory cells are found in the anterior and posterior segments. The acute stage of ARN is characterized by necrotizing retinitis of all retinal layers. The adjacent choroid shows severe choroiditis with vascular occlusion.

\section{Herpes Simplex Virus}

HSV-1 is a common cause of chorioretinitis in the clinic, of which the therapeutic approaches include not

\section{KARGER}

Fax +41613061234

E-Mail karger@karger.ch

www.karger.com (c) 2009 S. Karger AG, Basel

$1015-2008 / 09 / 0761-0045 \$ 26.00 / 0$

Accessible online at:

www.karger.com/pat
Haifeng Mei

Department of Ophthalmology, Renmin Hospital of Wuhan University

Jiefang Road 238, Wuhan 430060 (PR China)

Tel. +86278851 2243, Fax +86278805 7872

E-Mailmhf021471@yahoo.com 
only efficient therapy for antivirus, but also topical or systemic application of corticosteroid hormone. However, the relapse rate is high. Therefore, to explore new therapies is the responsibility of all oculists. These new therapies include the application of cytokine inhibitors, antimetabolism drugs, cytotoxicity drugs and a few biological agents, among which gene therapy is attracting more and more attention. Antisense technology has been applied in the clinic. In this study, we adopted HSV-1 to induce a chorioretinitis model, applied antisense oligonucleotides (ASON) targeting tumor necrosis factor- $\alpha$ (TNF- $\alpha$ ) for topical treatment, and then investigated its effect on the pathogenesis model with the aim to provide beneficial clues to treat chorioretinitis.

\section{Von Szily Model}

In 1924, Von Szily [3] first used rabbits as the experimental model to study the mechanism of HSV infection. In 1984, Whittum et al. [4] substituted mice for rabbits. HSV was injected into the anterior chamber of one eye leading to anterior uveitis with intact retina, while in the contralateral eye it mainly appeared to be necrotic chorioretinitis. It was postulated that after injection of HSV1 into the anterior chamber, the virus may migrate from the brain to the retina via retrograde axonal transport through the optic nerve, along the endocrine-optic path between the retina, resulting in necrotic chorioretinitis of the contralateral eye. However, the definite mechanism was not completely known, possibly because of the specific cellular immunity caused by HSV-1. Several immunocells and cytokines took part in the pathogenesis.

\section{Method and Materials}

\section{Antisense Oligonucleotides}

Since antisense technology has developed into a powerful tool for therapeutic purposes, antisense molecules can be used to cure any disease causing expression of a deleterious gene. Antisense molecules are commonly composed of single-stranded DNA, which are termed ASON. ASON usually consist of 15-20 nucleotides, which is complementary to their targeting mRNA. The mechanisms of action include blockage of translation and splicing. As a gene therapy, ASON has its own privilege of high selectivity and specificity. Although a few unresolved problems still exist, such as not enough acquaintance with the targeting gene and the efficiency of gene import, the antisense technique has been a therapeutic approach to treat many clinical diseases. The ASON (CGA AGT TCA GTA GAC AG) (Biognostik Co., Göttingen, Germany) used in this study is the reverse complement to bases 300-316 of the total sequence of murine TNF- $\alpha$, and it targets an exon of the coding region. Their specific combination will reduce the content of TNF- $\alpha$ in mice.

\section{HSV-1-Induced Chorioretinitis Model}

50 female $\mathrm{BALB} / \mathrm{c}$ mice were provided. The animals were aged 6-8 weeks and were maintained according to the ARVO Statement for the Use of Animals in Ophthalmic and Vision Research and according to the guidelines approved by the Institutional Animal Care and Use Committee. 2 mg ketamine and 400 ng mepivacaine hydrochloride were injected intraperitoneally for anesthesia, then $1 \times 10^{5}$ plaque-forming units of HSV-1 (KOS strain) were inoculated into the anterior chamber of the right eye under an operating microscope to induce a HSV-1 chorioretinitis model.

\section{Experimental Design}

50 mice were randomly divided into two different groups according to a random number graph (25 mice in each group). In one group, fluorescein isothiocyanate (FITC)-labeled ASON targeting TNF- $\alpha 2 \mu \mathrm{l}$ was injected subconjunctively in the left eye 1 day before and 1 and 4 days after the infection, while phosphate buffer solution was injected in the same way in another group.

\section{Clinical Investigation}

The mice were raised routinely after infection. Two days later we observed the changes of both eyes and accessed the clinical grades. Inflammation in the anterior chamber, vasodilatation of the cornea and iris, and formation of cataract and vitreous opacity were graded on a scale of 0 to $4+$ accordingly.

\section{Histological Examination}

Ten days later, all mice were killed by luxation of the cervical vertebrae and the eyes immediately removed. Both eyes of 15 mice in each group were fixed in $4 \%$ formaldehyde, routinely dehydrated and embedded in paraffin. The eyes were cut into $5-\mu \mathrm{m}$ sections and placed on 3-aminopropyltriethoxysilane-coated slides. The sections were stained with hematoxylin and eosin (HE) according to a standard protocol and mounted. The inflammatory cells were enumerated by means of a high-power $(\times 250)$ bright-field microscope under a $10 \times 10$ grid in six positions including the anterior chamber, iris, ciliary body, vitreous, choroid and retina. All counts were independently performed by two investigators in a masked fashion.

Measurement of the Content of TNF- $\alpha$ in Choroid and Retina

After execution, 10 left and right eyes were extracted from each group. The cornea was removed in the corona direction and then the lens and vitreous were removed. The surplus part was conserved in $-80^{\circ} \mathrm{C}$ liquid nitrogen, into which the volume of a dilution kit was added 3-5 times. The homogenate was placed in an ice bath for $1 \mathrm{~min}$ and then centrifuged in a radius of $5 \mathrm{~cm}$ at a rate of 2,000 rpm for $5 \mathrm{~min}$. The supernatant was taken and the content of TNF- $\alpha$ in the choroid and retina measured by standard ELISA according to the protocols recommended by the supplier.

\section{Statistical Analysis}

Clinical investigation was analyzed by means of Fisher's test. The number of inflammatory cells in each position was observed by histological observation, and the result was analyzed by $t$ test. $\mathrm{p}<0.05$ was considered to indicate a significant difference between two groups. 


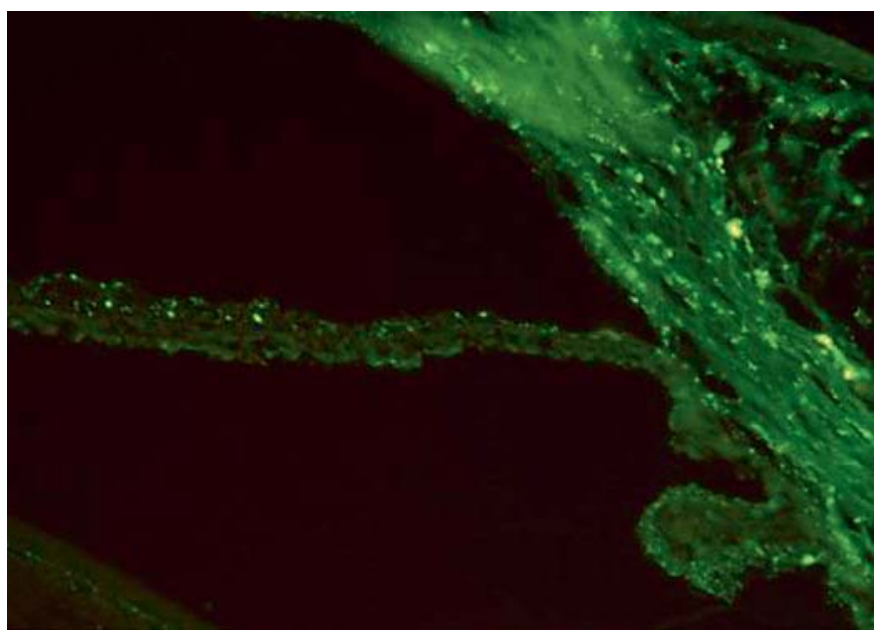

Fig. 1. Fluorescence staining of different tissues 1 day after injection of FITC ASON. The subconjunctiva, iris and ciliary body were strongly fluorescent-positive. $\times 400$.

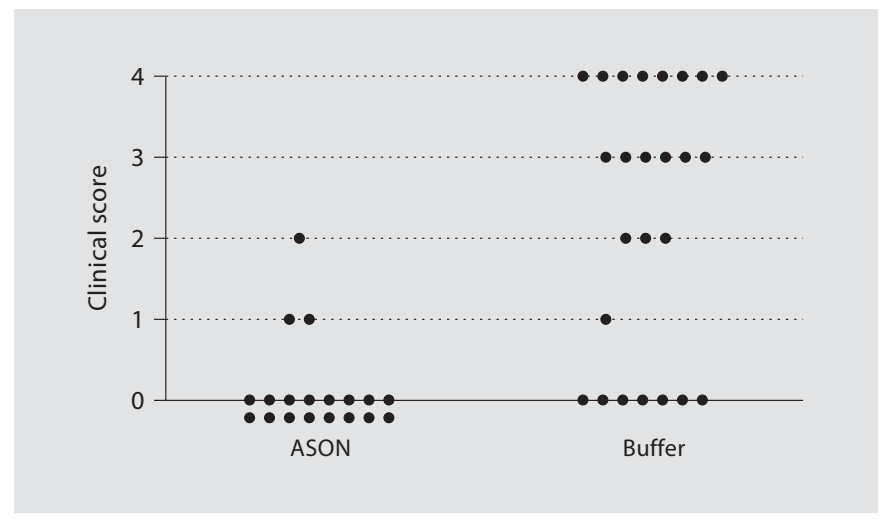

Fig. 2. Influence of TNF- $\alpha$ ASON on the inflammation of the left eye in BALB/c mice 2 days after HSV-1 infection. The inflammation was graded from 0 to $4+$ depending on the inflammation in the anterior chamber, vasodilatation of cornea and iris, and formation of cataract and vitreous opacity. Animals treated with ASON had less severe inflammation than mice treated with buffer. ${ }^{* *} \mathrm{p}<$ 0.01 indicated a significant difference between two groups.
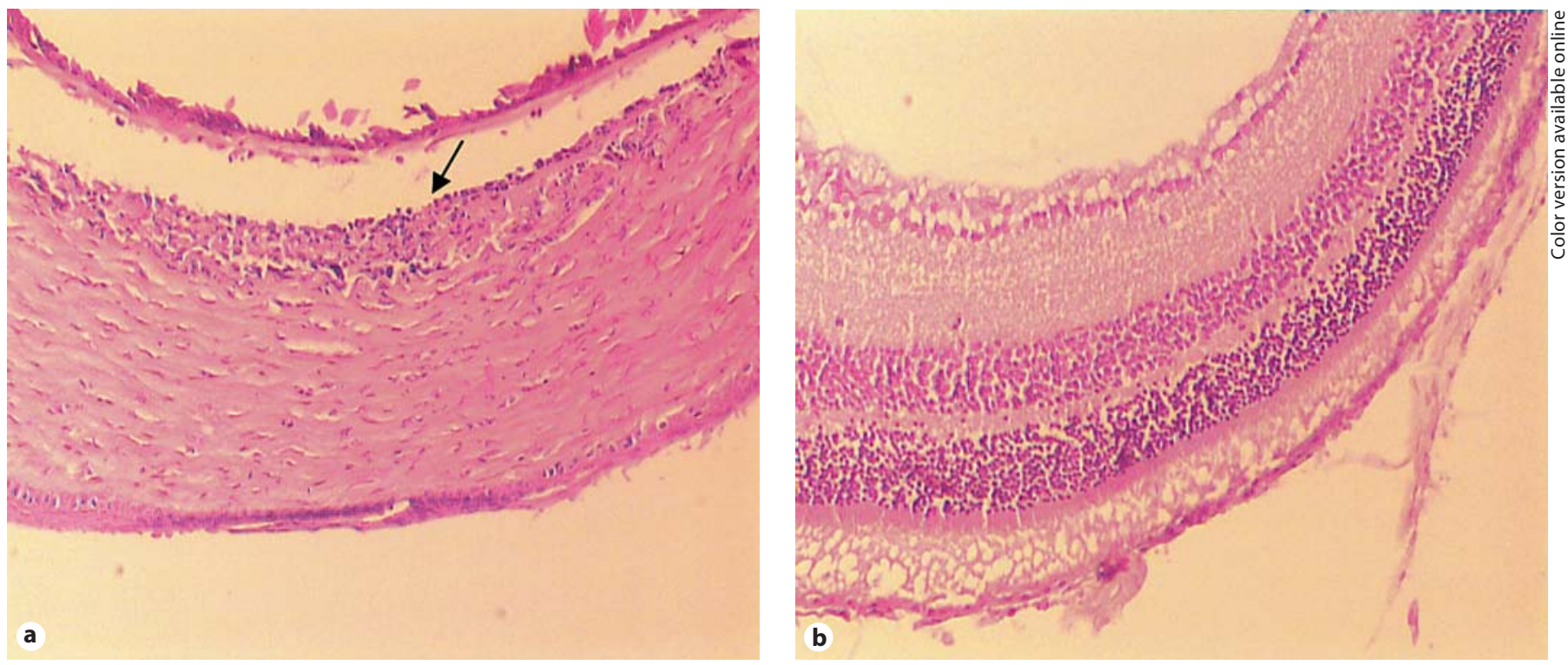

Fig. 3. Light microscopic image of the different tissues of the right eye after HSV-1 infection in the ASON group (anterior and posterior chambers). a Dropsical cornea stroma with infiltration of inflammatory cells; fibrin-like exudate and inflammatory cell (arrow) infiltration in the anterior chamber; distorted structure of iris and ciliary body. b No inflammatory cells in vitreous body; normal structure of choroids and retina. HE. $\times 400$.

\section{Results}

\section{Uptake (fig. 1)}

It was reported that FITC-labeled ASON were taken up after $15 \mathrm{~min}$ in vitro by cells taken from the spleen and lymph. The cells include macrophages, monocytes and lymphocytes. As for the subconjunctival injection, the epithelial barriers are bypassed. Intracellular fluorescence staining was investigated in the eye tissue of the iris, choroid and retina. 

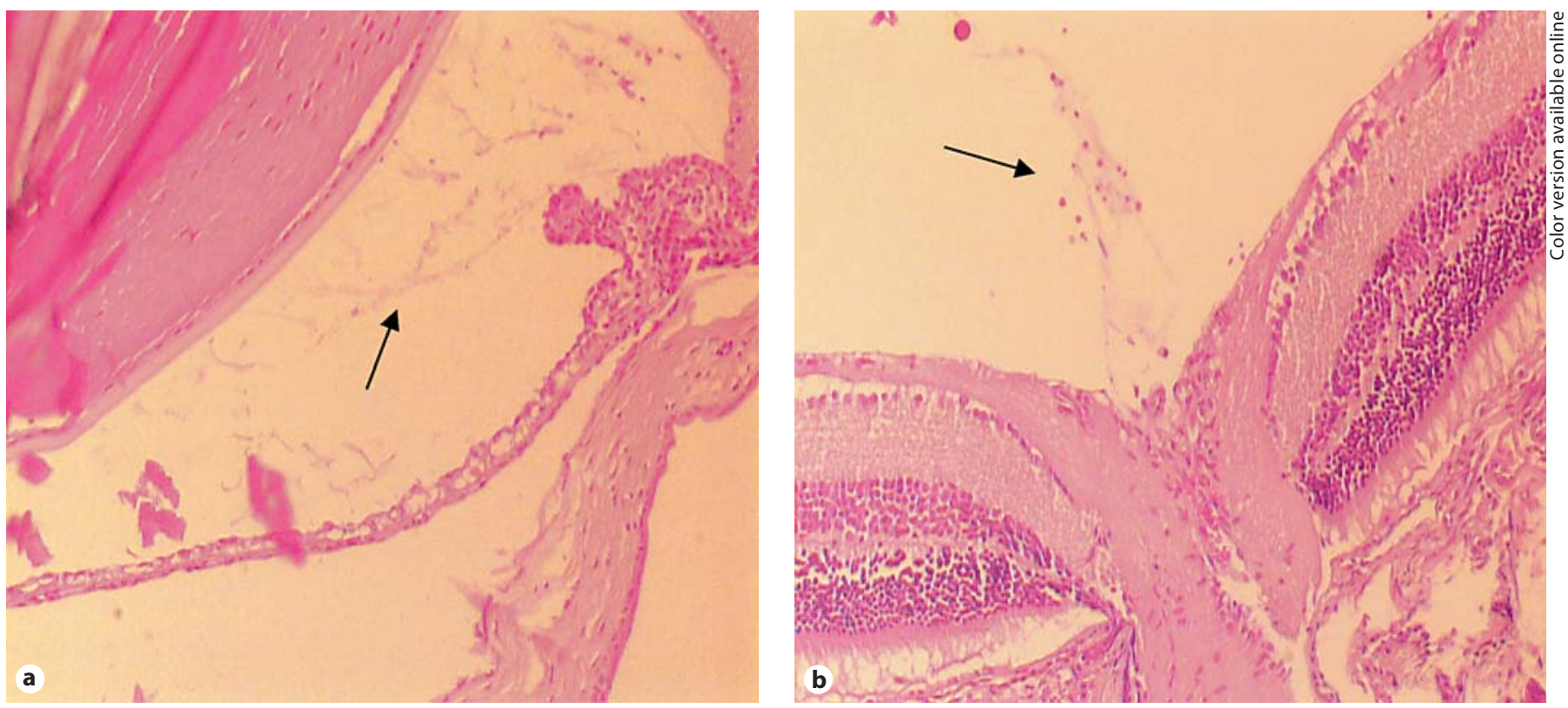

Fig. 4. Light microscopic image of the different segments of the left eye after HSV-1 infection in the ASON group (anterior and posterior segments). a Mildly dropsical cornea; several inflammatory cells (arrow) in the anterior chamber; normal structure of iris and ciliary body. b A few inflammatory cells (arrow) in vitreous; mildly disordered structure of the local choroids and retina. HE. $\times 400$.
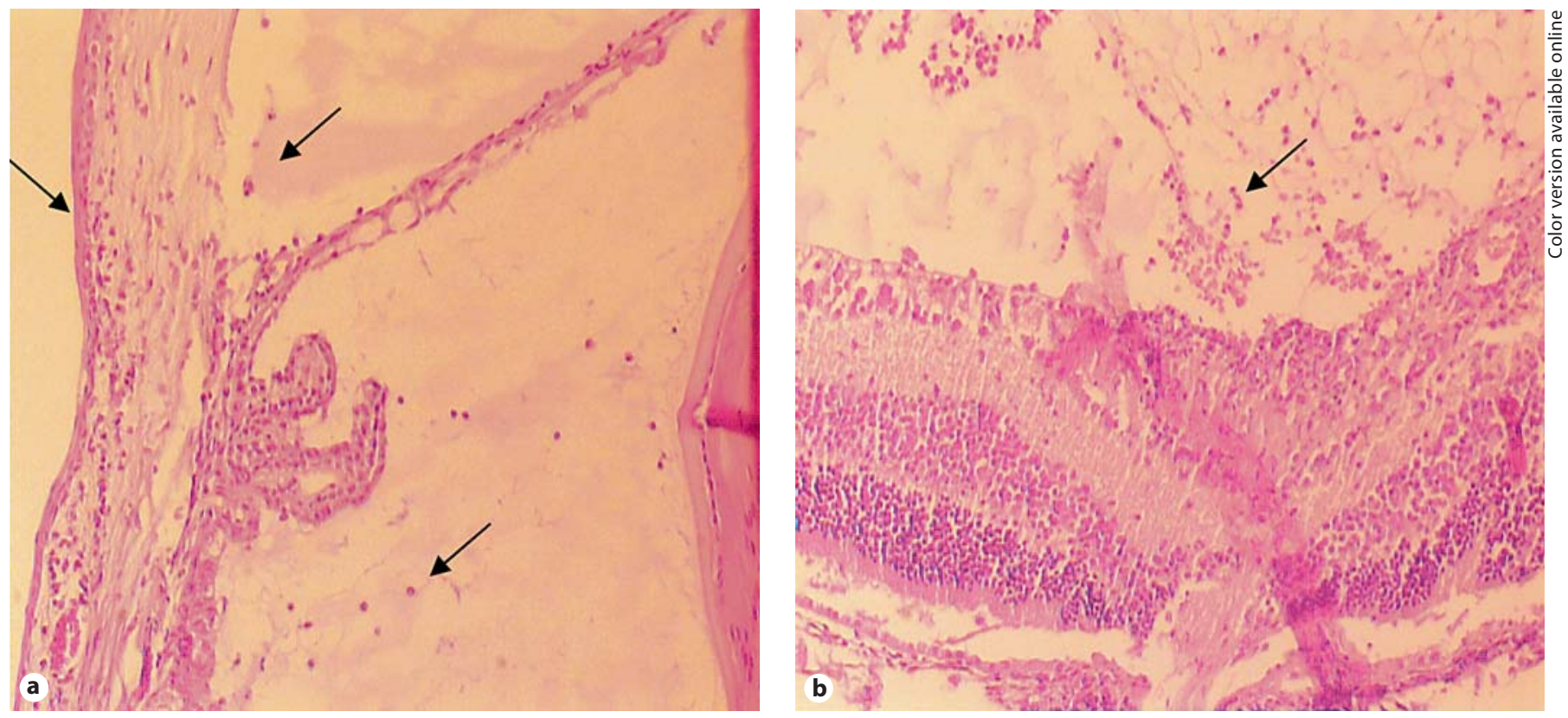

Fig. 5. Light microscopic image of the anterior segment of the left eye after HSV-1 infection in different treatment groups (ASON and PBS). a Mild dropsical cornea stroma with infiltration of a few inflammatory cells; a few inflammatory cells in the anterior chamber; normal structure of iris and ciliary body with a few inflammatory cells (arrows). b Numerous inflammatory cells (arrow) in vitreous body; abnormal structure of choroids and retina with swollen tissues and numerous infiltrated inflammatory cells. HE. $\times 400$. 


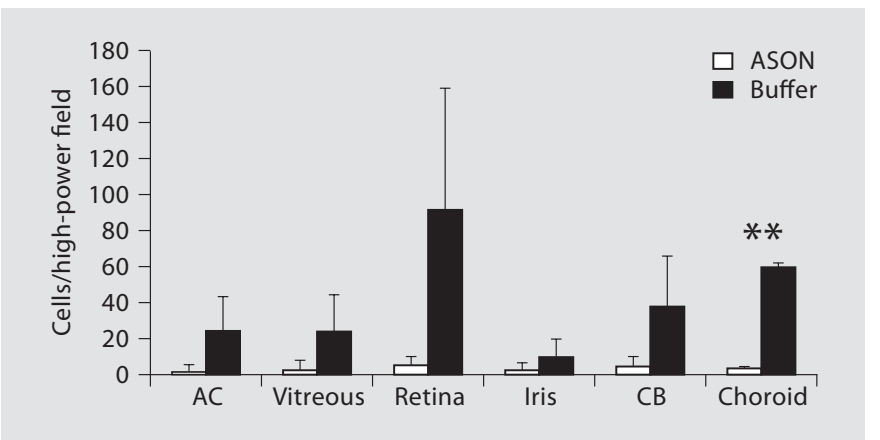

Fig. 6. Number of inflammatory cells counted in a high-power field $(\times 400)$ in six positions that include the anterior chamber $(\mathrm{AC})$, iris, ciliary body (CB), vitreous, choroids and retina. The number in the ASON group treated with ASON was significantly less than in the PBS group treated with buffer in each position. ${ }^{* *} \mathrm{p}<0.05$ indicates a significant difference between two groups.

\section{Clinical Investigation}

After HSV-1 infection, there were severe inflammatory reactions in all of the inoculated eyes: vasodilatation of the iris, considerable inflammatory effusion in the anterior chamber, enlarged pupils, lens opacity, etc., with grades from 3 to 4 . In the ASON group there were inflammatory reactions in 3 left eyes among a total of 25 , while in the PBS group there were 18 left eyes among a total of 25 . The incidence was $12 \%$ in the ASON group, compared with $72 \%$ in the PBS group. As far as the clinical grade was concerned, 22 eyes were grade 0 and 3 eyes were grade 1-2 in the ASON group, while 11 eyes were grade $0-2$ and 14 eyes were grade 3-4 in the PBS group.

\section{Histological Examination (fig. 2-5)}

HSV-1-injected eyes showed dropsical cornea stroma, fibrin-like exudates and inflammatory cell infiltration in the anterior chamber, disordered structure of the iris and ciliary body with infiltration of inflammatory cells. There was no inflammation in vitreous, and the structure of choroid and retina was normal with no obvious inflammation.

In the ASON group, 2 eyes among the uninoculated eyes were inflamed, mostly in the vitreous. They appeared to have mildly dropsical cornea, several inflammatory cells in the anterior chamber, and a normal structure of the iris and ciliary body. There were several inflammatory cells (mainly lymphocytes, monocytes and PMN) infiltrated in the posterior vitreous body and a mildly disordered structure of topical choroids and retina. The other 13 eyes had no infection with no obvious inflammatory cells.

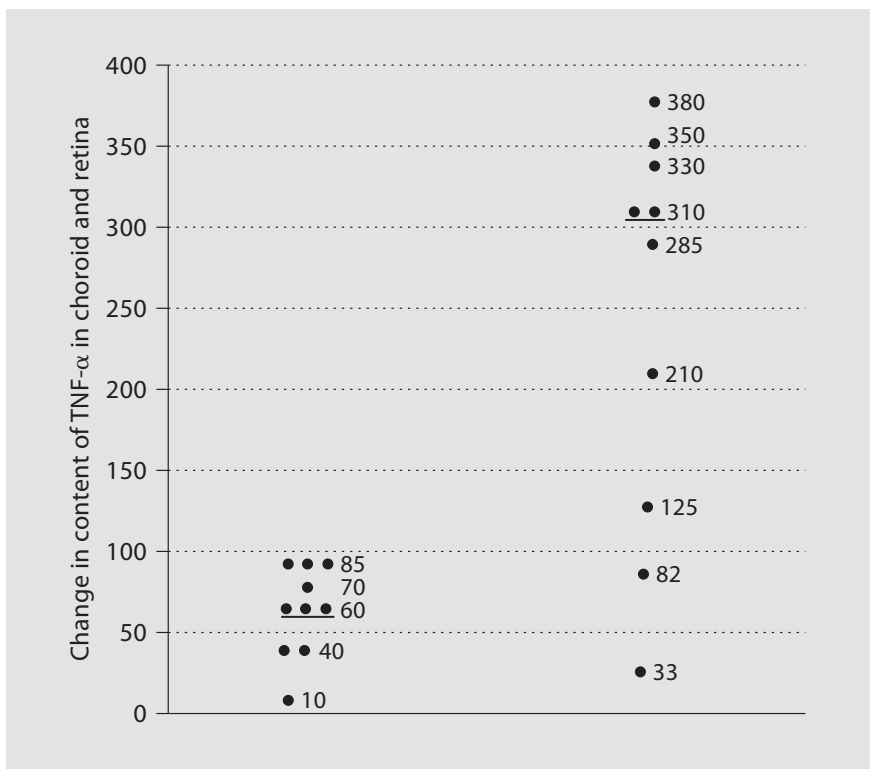

Fig. 7. Influence of TNF- $\alpha$ ASON on the uninfected eye of BALB/ $c$ mice on day 10 after HSV-1 infection. The content of TNF- $\alpha$ in the choroids and retina was significantly reduced after TNF- $\alpha$ ASON treatment compared with buffer treatment. ${ }^{*} \mathrm{p}<0.05$ indicates a significant difference between two groups. Crossbar indicates the mean.

In the PBS group, 12 left eyes had necrotic chorioretinitis, mainly mildly dropsical cornea, several inflammatory cells in the anterior chamber and iris, and a ciliary body with a basically normal structure. There was inflammation in the posterior vitreous. The structures of choroid and retina were disordered with swollen tissues and many infiltrated inflammatory cells. The other 3 eyes had a normal structure.

After statistical analysis, the inflammatory cell count between two groups showed a significant difference in the ciliary body, choroid and retina $(\mathrm{t}=1.842,1.983$, $2.114, \mathrm{p}<0.05)$.

\section{Content of TNF- $\alpha$ in Choroid and Retina (fig. 6, 7)}

The ELISA results showed that the content of TNF- $\alpha$ of choroid and retina in the left eyes in the ASON group was $60 \pm 1.25 \mathrm{pg}$, while in the PBS group it was $305 \pm$ $1.03 \mathrm{pg}$. There was a statistical difference between two groups $(t=2.833, \mathrm{p}<0.01)$. The TNF- $\alpha$ content of the choroid and retina in the right eyes in the ASON group was $621 \pm 4.35 \mathrm{pg}$, while in the PBS group it was $718 \pm$ $2.23 \mathrm{pg}$. There was no statistical difference between the two groups $(t=8.134, p>0.05)$. 


\section{Discussion}

TNF- $\alpha$ is produced by many cell types, among which are mononuclear macrophages, $\mathrm{T}$ cells, and natural killer cells. It is now known to possess many cell-activating and proinflammatory activities. A few researchers have indicated that TNF- $\alpha$ injected into vitreous may lead to destruction of the blood-eye barrier, increased protein in aqueous fluid, entrance for a few inflammatory cells such as polymorphocytes, histoleukocytes, macrophages, lymphocytes into aqueous fluid and vitreous with apparent panuveitis. Especially after observation of widespread TNF- $\alpha$ in the HSV-1 inoculated eyes, we can come to the conclusion that TNF- $\alpha$ may play an important role in HSV-1-induced inflammation and TNF- $\alpha$ inhibitor may be a candidate therapeutic approach to cure uveitis efficiently. There are now a few reports about the application of anti-TNF- $\alpha$ drugs such as inflixamb and etanercept, but the repeated application of these drugs that target the TNF- $\alpha$ antibody directly has the disadvantage of potential systemic side effects. Alternatively, some other ways of inhibiting TNF- $\alpha$ have been proposed [5-10].

ASON have a considerable therapeutic ability because of their ability to inhibit the synthesis of specific proteins. ASON targeting TNF- $\alpha$ has been used to cure immuneinduced disease such as Crohn's disease and allergy. Inhibition of gene expression with ASON has also been applied for the treatment of some ocular disease. ASON targeting vascular endothelial growth factor was delivered to the retina in monkey models to reduce iris neovascularization. Henry et al. [11] reported that formivirsen de- signed to inhibit human CMV was approved for treatment of CMV retinis. Wasmuth et al. [12] adopted ASON targeting TNF- $\alpha$ to treat topical keratitis induced by HSV-1 to show its obvious inhibition in the release of TNF- $\alpha$ so as to change the course of keratitis.

In this study, we adopted HSV-1 to induce chorioretinitis and reproduce the Von Szily model, and then used ASON targeting TNF- $\alpha$ to observe the affection on pathogenesis. After treatment with TNF- $\alpha$ ASON, the incidence of inflammatory reactions in the ASON group was lower than in the PBS group (12 and 72\%). The histological results showed that the inflammatory cells were reduced in the choroid, ciliary body and retina. The content of TNF- $\alpha$ in choroid and retina in the ASON group was lower than in the PBS group. There are several possible mechanisms by which TNF- $\alpha$ ASON treatment may have achieved improvement of chorioretinitis. TNF- $\alpha$ ASON can block the production of TNF- $\alpha$ that enhance $\mathrm{T}$-cell differentiation and proliferation, while $\mathrm{T}$ cells may accelerate the cellular infiltration and inflammation-induced retinal destruction in the Von Szily model. TNF- $\alpha$ expression was reduced and RPE cells activated. Müller cells may be in part responsible for the improvement of acute chorioretinitis. It is possible that TNF- $\alpha$ ASON results in reduced antigen presentation, reduced leukocyte proliferation, and reduced apoptosis of APC.

Taken together, TNF- $\alpha$ ASON can reduce intraocular inflammation and improve the pathogenesis of chorioretinitis. It is strongly commended that ASON as a gene therapy may play an important role in the treatment of $\mathrm{ARN}$ in the future.

\section{References}

1 Lustig MJ, Cunningham ET Jr: Use of immunosuppressive agents in uveitis. Curr Opin Ophthalmol 2003;14:399-412.

$\checkmark 2$ Hartung HP, Heiniger K: Non-specific mechanisms of inflammation and tissue damage in MS. Res Immunol 1989;140:226233.

3 Von Szily A: Experimentelle endogene Infektionsübertragung von Bulbus zu Bulbus. Klin Monatsbl Augenheilkd 1924;72:593.

$\checkmark 4$ Whittum JA, McCulley JP, Niederkorn JY, Streilein JW: Ocular disease induced in mice by anterior chamber inoculation of herpes simplex virus. Invest Ophthalmol Vis Sci 1984;25:1065.
5 Lewis ML, Culbertson WW, Post JD, et al: Herpes simplex virus type-1: a cause of the acute retinal necrosis syndrome. Ophthalmology 1989;96:875-878.

6 Ngugen QD, Uy HS, Mercbant A, et al: Effect of Fas and Fas ligand deficiency in resistance of C57BL/6 mice to HSV-1 keratitis and chorioretinitis. Invest Ophthalmol Vis Sci 2001; 42:2505-2509.

7 Emmett T, Cunningham A Jr, Stalder P, et al: Localization of TNF-R mRNA in normal and HSV-infected mouse eyes. Invest Ophthalmol Vis Sci 1997;38:9-15.

$\checkmark 8$ Joseph RA, Rai D, Dua HS, et al: Infiximab in the treatment of refractory posterior uveitis. Ophthalmology 2003;110:1449-1453.

$\checkmark 9$ Reiff A, Takei S, Sadeghi S, et al: Etanercept therapy in children with treatment-resistant uveitis. Arthritis Rheum 2001;44: 1411-1415.
10 Coxon A, Bolon B, Estrada J, et al: Inhibition of IL-1 but not TNF suppresses neovascularization in rat models of corneal angiogenesis and adjuvant arthritis. Arthritis Rheum 2002;46:2604-2612.

11 Henry SP, Miner RC, Drew WL, et al: Antiviral activity ocular kinetics of antisense oligonucleotides designed to inhibit CMV replication. Invest Ophthalmol Vis Sci 2001; 42:2646-2651.

12 Wasmuth S, Bauer D, Yang Y, et al: Topical treatment with antisense oligonucleotides targeting tumor necrosis factor- $\alpha$ in herpetic stromal keratitis. Invest Ophthalmol Vis Sci 2003;44:5228-5235. 